Canadian

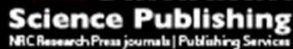

Canadian Geotechnical Journal Revue canadienne de géotechnique

\title{
Rainfall-triggered Slope Instabilities under a Changing Climate: Comparative Study using Historical and Projected Precipitation Extremes
}

\begin{tabular}{|r|l|}
\hline Journal: & Canadian Geotechnical Journal \\
\hline Manuscript ID & cgj-2015-0602.R2 \\
\hline Manuscript Type: & Article \\
\hline Complete List of Authors: & $\begin{array}{l}\text { Robinson, Joe; Mississippi State University } \\
\text { Vahedifard, Farshid; Mississippi State University, Department of Civil and } \\
\text { Environmental Engineering } \\
\text { AghaKouchak, Amir; University of California, Irvine }\end{array}$ \\
\hline Keyword: & $\begin{array}{l}\text { Landslides; Climate change; Extreme Precipitation; Non-stationary; } \\
\text { Unsaturated soil; Numerical modeling; Transient seepage, Hydro- } \\
\text { mechanical coupling }\end{array}$ \\
\hline \multicolumn{2}{|c}{} \\
\hline
\end{tabular}

SCHOLARONE ${ }^{1 m}$

Manuscripts 


\title{
Rainfall-triggered Slope Instabilities under a Changing Climate: Comparative Study using Historical and Projected Precipitation Extremes
}

\author{
Joe D. Robinson ${ }^{1}$, Farshid Vahedifard ${ }^{2}$, Amir AghaKouchak ${ }^{3}$ \\ ${ }^{1}$ Geotechnical Engineer, Terracon Consultants, Inc., 51 Lost Mound Dr., Suite 135, Chattanooga, TN \\ 37406; Formerly Graduate Student, Dept. of Civil and Environmental Engineering, Mississippi State \\ University, Mississippi State, MS 39762, USA. email: Jody.Robinson@terracon.com \\ ${ }^{2}$ Corresponding Author, Assistant Professor, Dept. of Civil and Environmental Engineering, Mississippi \\ State University, Mississippi State, MS 39762, USA. email: farshid@cee.msstate.edu \\ ${ }^{3}$ Associate Professor, Department of Civil and Environmental Engineering, University of California, \\ Irvine, CA 92697, USA. e-mail: amir.a@uci.edu
}

\begin{abstract}
This study aims to quantitatively assess the impact of extreme precipitation events under current and future climate scenarios on landslides. Rainfall-triggered landslides are analyzed primarily using extreme precipitation estimates, derived using the so-called stationary assumption (i.e., statistics of extreme events will not vary significantly over a long period of time). However, extreme precipitation patterns have shown to vary substantially due to climate change, leading to unprecedented changes in the statistics of extremes. In this study, a nonstationary approach, applied to climate model simulations, is adopted to project the upper bound of future precipitation extremes. Future precipitation estimates are obtained from the Coupled Model Intercomparison Project Phase 5 (CMIP5) simulations. Baseline (historical) and projected (future) precipitation extremes are obtained for a study area near Seattle, Washington. The precipitation patterns are integrated into a series of fully coupled 2D stress-unsaturated flow finite element simulations. The responses of the baseline and projected models at a 7-day rainfall duration obtained for a 50-year recurrence interval are compared in terms of the local strength reduction factor, displacements, matric suctions, and suction stresses. The results indicate that the usage of historical rainfall data can lead to underestimations in the hydro-mechanical
\end{abstract}


behavior of natural slopes where locally increased transient seepage rates occur from the upper bound of future extreme precipitation estimates.

Keywords: Landslides; Climate change; Extreme Precipitation; Non-stationary; Unsaturated soil; Numerical modeling; Hydro-mechanical coupling; Transient seepage

\section{INTRODUCTION}

Landslides are natural hazards that often pose threats on both the societal and economical levels. In the United States, landslides are responsible for more than \$1.6 billion in annual losses (e.g., Schuster and Highland 2001). They may be attributed to destabilizing factors such as soil desiccation and tensile cracking, land and surface erosion, soil fissuring and softening, and seismicity (e.g., Leshchinsky et al. 2015). However, landslides are most frequently accredited to dynamic processes, namely, significant seasonal and long-term variations in rainfall; and under these type of extreme climatic conditions the aforementioned weakening mechanisms can accelerate landslide rates. Rainfall variations can have immense impacts on soil moisture and strength, and the near-surface groundwater field. The groundwater field directly impedes the activation of deep-seated landslides, which are classified as slopes failures involving the movement of the surficial mantle and underlying bedrock (e.g., Coe and Godt 2012). Since deepseated landslides are generally sensitive to extremes in the hydraulic cycle, protracted drought, which increases groundwater extraction and, thus impedes groundwater recharge, can lead to cessation of these landslides (e.g., Coe and Godt 2012). In contrast, shallow landslides include translational slope failures that are a few meters thick, comprising of poorly consolidated soil mantle and underlying bedrock (e.g., Cascini et al. 2010; Lu et al. 2012). The frequency and magnitude of shallow landslides are sensitive to meteo-climatic factors such as extreme rainfall events, rapid snowmelt, and antecedent rainfall (e.g., Sidle 2007; Melchiorre and Frattini 2012). 
These landslides may be delineated by two failure mechanisms: diffuse and localized failures (e.g., Cascini 2010). The diffuse failure mechanism represents a unique characteristic of soils in a fully or partially undrained state exhibiting very loose or metastable structures (e.g., earthquake-induced liquefaction of a sand layer), where the effective stress approaches zero as the pore-water pressure increases. The localized failure mechanism, however, represents soils in a drained state and is attributed to transient localized pore-water pressures arising from particular geological settings and hydraulic boundary conditions (Cascini 2013; Casini 2013).

Landslide processes are typically assessed at local to regional scales (e.g., Coe and Godt 2012; Melchiorre and Frattini 2012). However, discerning these processes necessitates a comprehensive understanding of how they are affected by a changing climate (e.g., Farahmand and AghaKouchak 2013). Coe and Godt (2012) identified fourteen technical approaches to assess the impacts of climate change on landslide activity. Coe and Godt (2012) categorized these approaches into three groups: 1) long-term monitoring of climate change and the corresponding response from landslides; 2) surveying approaches manifesting the association between climate change and landslides from historical data; and 3) future approaches that establish patterns between climate change and historical landslide activation. One shortcoming of the aforementioned approaches is that they are partially reliant on the so-called stationary assumption (i.e., statistics of extreme events will not vary significantly over a long period of time) (Coe and Godt 2012). However, climate change is anticipated to increase the frequency, intensity, and duration of climatic extremes in the future (e.g., Cheng and AghaKouchak 2014). There are two major issues that obstruct advancement in our understanding how landslides are affected by a changing climate, which include the uncertainty in forecasting landslide activation due to heavy precipitation and improbability in predicting precipitation and storm patterns (e.g., 
Coe and Godt 2012; Melchiorre and Frattini 2012). Moreover, landslide studies typically project mean precipitation data as it is very difficult to estimate the variations in the frequency and magnitude of extreme rainfall events (e.g., Coe and Godt 2012).

Among recent climate trends, extreme precipitation is recognized as one of the major causes for several instabilities in natural and engineered earthen structures (e.g., NRC 2008, 2013; Sorooshian et al. 2011). In fact, some areas (e.g., Northeast United States) throughout the United States experienced as much a 67\% increase in heavy precipitation from 1958 to 2007 (USGCRP 2009). Similar trends have been reported throughout other parts of the world like the Korean Peninsula (e.g., KMA 2008), and such trends have prompted several rainfall-triggered instabilities in natural and engineered earthen structures (e.g., Leshchinsky et al. 2015). These cases highlight a crucial need for considering the increased intensity of extreme precipitation driven by climate change in the analysis, maintenance, and monitoring of existing infrastructure, as well as the design of future infrastructure (e.g., NRC 2008, 2013; Crozier 2010; ASCE 2015).

The hydro-mechanical response of earthen structures to extreme precipitation events is commonly analyzed using Intensity-Duration-Frequency (IDF) curves (Cheng and AghaKouchak 2014). These curves are established using historical rainfall data. Failing to recognize changes in statistics of extremes events (i.e., non-stationary condition), such as increased rainfall intensity, when analyzing the stability of an earthen structure can lead to significant underestimations in the expected rainfall events that a structure may experience during its lifetime (e.g., Gregersen et al. 2013; Cheng et al. 2014; Vardon 2015). Thus, the impacts of future (projected) precipitation patterns on the short and long term behavior of natural and engineered earthen structures is an issue that needs to be further evaluated. 
This study quantitatively investigates natural slope instabilities due to extreme precipitation events under climatic variations. Many of the weaknesses observed in previous studies (e.g., Coe and Godt 2012) lies in the input (e.g., assuming a stationary climate) and output data, rather than the methodology. To consider these weaknesses, as well as variations in the statistics of the future climate, the current study adopts a non-stationary approach, applied to climate model simulations, to analyze projected annual precipitation maxima. This approach would yield less uncertainty in the analysis of landslide modeling and improve our understanding of climate-induced changes in future extreme rainfall events (e.g., Cheng and AghaKouchak 2014; Cheng et al. 2014). Baseline and projected precipitation extremes correspond to an area near Seattle, Washington (WA). Both historical (baseline) and projected precipitation patterns are integrated into a series of fully coupled 2D transient unsaturated seepage finite element (FE) simulations. The responses of the baseline and projected FE models at a 7-day rainfall duration obtained for a 50-year recurrence interval are compared in terms of the local strength reduction factor (SRF), displacements, matric suctions (i.e., difference between pore air and pore-water pressure), degrees of saturation, and suction stresses.

\section{INTENSITY OF EXTREME PRECIPITATION EVENTS}

Seattle, WA is selected as the study area for acquiring the historical and future IDF curves. This area is frequently susceptible to shallow and deep-seated landslides that are primarily triggered by rainfall (e.g., Lu et al. 2012). A major rainfall-triggered landslide recently occurred about 100 kilometers north of Seattle in Snohomish County, WA, in March 2014. The landslide was characterized as a deep-seated slope failure. It has been reported that the spring of 2014 was the wettest on record in Seattle. In fact, approximately 48 centimeters of heavy rain 
had fallen at the Sea-Tac Airport in Seattle from February to March 2014. The Snohomish County landslide resulted in capital losses in excess of $\$ 50$ million (Keaton et al. 2014). It is noted that, the extreme precipitation conditions could have been a contributing factor towards the catastrophic slope failure (e.g., Iverson et al. 2015).

To compare the effects of historical and future precipitation extremes on rainfalltriggered slope instabilities, this study uses two sets of IDF curves: baseline (historical) and projected (future). The baseline IDF curves are derived using a stationary framework, similar to the method outlined in Bonnin et al. (2006), which uses the National Oceanic and Atmospheric Administration (NOAA) Atlas 14 to obtain historical rainfall data. Current infrastructure design codes rely heavily on NOAA Atlas 14. The fundamental analysis outlined in Bonnin et al. (2006) is based on the Generalized Extreme Value (GEV) distribution assuming a stationary climate. This approach adopts ground-based observations of precipitation extremes (i.e., annual maxima) from the highest precipitation amount for various rainfall durations (e.g., 3- and 7-day). Furthermore, the standard GEV distribution is delineated as such (Coles 2001):

$$
\Psi(\mathrm{x})=\exp \left\{-\left(1+\xi\left(\frac{\mathrm{x}-\mu}{\sigma}\right)\right)^{-\frac{1}{\xi}}\right\}, 1+\xi\left(\frac{\mathrm{x}-\mu}{\sigma}\right)>0
$$

The GEV distribution is described using the location $(\mu)$, scale $(\sigma)$ and shape $(\xi)$ parameters. In a stationary approach, the statistical properties of the distribution are independent of time, whereas the parameters [i.e., $\theta=(\mu, \sigma, \xi)$ ] under a non-stationary assumption are explicitly defined as a function of time.

In this study, the approach outlined in Cheng and AghaKouchak (2014) is adopted to derive projected non-stationary IDF curves. This approach assumes $\mu$ to be time-dependent, 
while $\sigma$ and $\xi$ remain time invariant. Cheng and AghaKouchak (2014) use a linear time dependence whereby $\mu$ can be defined as follows:

$$
\mu(t)=\mu_{1} t+\mu_{0}
$$

Once the annual maxima are acquired from the highest precipitation amount (from historical rainfall data) for various rainfall durations, $\mu(t)$ is predicted based on the $95^{\text {th }}$ percentile of Differential Evolution Markov Chain (DE-MC) sampled location parameters (i.e., $\widetilde{\mu}$ ) over time (Cheng et al. 2014). For different exceedance probabilities $(p)$, or recurrence intervals, the projected precipitation extremes can be defined as:

$$
\mathrm{q}_{\mathrm{p}}=\left(\left(-\frac{1}{\ln \mathrm{p}}\right)^{\xi}-1\right) \frac{\sigma}{\xi}+\widetilde{\mu},(\xi \neq 0)
$$

where $q_{p}$ represents the predicted future rainfall intensity.

The model parameters and uncertainty estimates for IDFs are estimated using a Bayesian approach available from the Nonstationary Extreme Value Analysis (NEVA) software developed by Cheng et al. (2014). The sampling approach used for estimating the parameters deduced by the Bayesian approach relies on DE-MC, a powerful tool commonly used for generating large numbers of realizations from the posterior distributions of the model parameters (e.g., Ter Braak 2006; Vrugt et al. 2009; Cheng and AghaKouchak 2014). In this study, precipitation estimates are obtained from the Coupled Model Intercomparison Project Phase 5 (CMIP5) simulations. Historical (1950-2009) and future (2040-2099) rainfall simulations available from the CMIP5 Representative Concentration Pathway (RCP) 8.5 are selected as inputs for deriving historical and future IDFs.

Future projections from 20 separate CMIP5 climate model simulations are used in a nonstationary model to derive future IDFs, where each single point represents an ensemble mean for 
given duration and return period. In addition to the mean, for each duration and return period, we also consider the $95^{\text {th }}$ percentile of the 20 climate models as a conservative estimate of the precipitation extremes. An ensemble includes a set of equally likely members from the climate model simulations. Based on Mann-Kendall trend test and Bayes factor statistics from NEVA (Cheng et al. 2014), a non-stationary model fits most ensemble members of future projections better than the commonly used stationary approach. In the non-stationary approach, GEV and the Mann-Kendall trend test are fitted separately to each ensemble member.

The current study considers a 7-day rainfall duration obtained for a 50-year recurrence interval for the Seattle region. Figure 1 presented below embodies the rainfall data implemented in this study. As can be seen, there is a significant difference between the baseline (Figure 1a) and the $95^{\text {th }}$ percentile of the projected (Figure $1 \mathrm{~b}$ ) rainfall intensities for each rainfall duration and respective recurrence interval. The relative change (Figure 1c) between the baseline and projected rainfall intensities mostly increases with a decreasing and increasing rainfall duration and recurrence interval, respectively. For example, the projected 1-day rainfall intensity for the 50 -year recurrence interval is approximately $65 \%$ greater than the baseline intensity. On the other hand, the 7-day projected rainfall intensity for the same recurrence interval is only about $53 \%$ higher than that obtained under the stationary approach. Furthermore, the relative difference between the baseline and projected rainfall intensities for the 1- and 7-day rainfall durations increases to $36 \%$ and $43 \%$, for the 2 -yr recurrence interval. Further information regarding the non-stationary framework implemented in this study can be found in Cheng and AghaKouchak (2014). 


\section{FULLY COUPLED NUMERICAL MODELING OF TRANSIENT UNSATURATED SEEPAGE}

A fully coupled FE analysis is executed to capture the behavior of a natural earthen slope under steady-state and transient unsaturated seepage conditions. The analysis is simulated using the 2D FE commercial code RocScience $\mathrm{RS}^{2}$. Biot's fully coupled pore pressure-stress equation is implemented in $\mathrm{RS}^{2}$ to capture the nonlinear behavior of the soil, where the fluid-solid coupling is accomplished through conditions of compressibility and continuity (e.g., Smith and Griffiths 1997) as follows:

$$
\frac{\mathrm{K}^{\prime}}{\gamma_{\mathrm{w}}}\left[\mathrm{k}_{\mathrm{x}} \frac{\partial^{2} \mathrm{u}_{\mathrm{w}}}{\partial \mathrm{x}^{2}}+\mathrm{k}_{\mathrm{y}} \frac{\partial^{2} \mathrm{u}_{\mathrm{w}}}{\partial \mathrm{y}^{2}}+\mathrm{k}_{\mathrm{z}} \frac{\partial^{2} \mathrm{u}_{\mathrm{w}}}{\partial \mathrm{z}^{2}}\right]=\frac{\partial \mathrm{u}_{\mathrm{w}}}{\partial \mathrm{t}}-\frac{\partial \mathrm{p}}{\partial \mathrm{t}}
$$

where $K^{\prime}$ demarcates the bulk modulus of the soil; $\gamma_{w}$ represents the unit weight of water; $u_{w}$ is the pore-water pressure; and $p$ is the mean total stress. To obtain equilibrium in $2 \mathrm{D}$ space, and in the absence of body forces, the gradients of the pore-water pressure in Biot's governing equation are used to augment the corresponding gradients of effective stress (e.g., Smith and Griffiths 1997). Moreover, Biot's governing equation is analyzed for equilibrium in $\mathrm{RS}^{2}$ for each respective time increment under steady-state and transient unsaturated seepage induced by the imposed baseline and projected infiltration boundary conditions.

Among others, the effective degree of saturation $\left(\mathrm{S}_{\mathrm{e}}\right)$ and suction stress $\left(\sigma^{\mathrm{s}}\right)$ are two parameters of interest that influence the strength of unsaturated soils (Lu et al. 2010; Robinson and Vahedifard 2016; Vahedifard et al. 2016a). Soil strength is the primary factor contributing to the stability of any earthen structure (e.g., Fredlund and Rahardjo 1993; Vanapalli et al. 1996; Vahedifard et al. 2015a, 2016b). The interactive thermodynamic free energy collectively represented by the suction stress in unsaturated soils can exist in the form of van der Waals forces, electric double-layer forces, surface tension, and soil-fluid air-interface forces resulting 
from matric suction (e.g., Lu et al. 2010). The current study employs the following equation for $\sigma^{\mathrm{s}}$ proposed by Lu et al. (2010):

$$
\sigma^{s}=-S_{e}\left(u_{a}-u_{w}\right)
$$

The closed-form solution for $\sigma^{\mathrm{s}}$ is an extension of Bishop's (1959) effective stress representation. Lu et al. (2010) verified the suction stress equation using experimental data obtained from 20 different soil types found in the literature. In addition, the suction stress-based effective stress representation has been used to assess active earth pressures (e.g., Vahedifard et al. 2015b), slope stability (e.g., Griffiths and Lu 2005; Vahedifard et al. 2016a), bearing capacity (e.g., Vahedifard and Robinson 2016), and analysis of reinforced earthen structures (e.g., Vahedifard et al. 2016c) in unsaturated soils. The effective degree of saturation is defined as follows:

$$
S_{e}=\frac{S-S_{r}}{1-S_{r}}
$$

where $S$ represents the pore-water saturation and $S_{r}$ is the residual saturation.

\section{NUMERICAL MODEL AND INPUT PARAMETERS}

A homogenous silty soil slope (Figure 2) is used to illustrate the impact of the baseline and projected precipitation extremes on the hydro-mechanical behavior of a natural slope. The model includes a 15-m high slope with 56-degree inclination. Similar slope geometries are reported in the literature for landslide modeling in the Seattle area (e.g., Lu et al. 2012). The analysis implements the classic effective shear strength parameters (i.e., $c^{\prime}$ and $\phi^{\prime}$ ) along with van Genuchten (1980)-Mualem (1976)'s soil-water characteristic curve (SWCC) and hydraulic conductivity function (HCF). The mechanical and hydraulic proprieties of the soil used in this study are adopted after Lu et al. (2012). The SWCC and HCF fitting parameters $n$ and $\alpha$ are an 
indicative of the soil's pore-size distribution and the air-entry pressure, respectively. The SWCC and HCF for the silty soil used in the FE effective stress analysis are displayed in Figure 3. In addition, the soil properties are presented in Table 1.

As displayed in Figure 2, a FE mesh consisting of 1,380 eight-node quadrilateral elements is employed to discretize the soil material. The density of the elements is refined within the top 2 meters of the slope to capture the higher expected displacements and transient localized pore-water pressure increases in the soil attributed to the imposed rainfall intensities.

As can be seen in Figure 2, the left and right sides of the domain are pinned, enabling movement in the vertical direction while restricting movement in the horizontal direction. Additionally, the bottom boundary of the domain is fixed, restricting movement in both the horizontal and vertical directions. For hydraulic boundary conditions, the baseline and projected rainfall intensities (Figure 1) are imposed along the surface infiltration boundary of the model slope.

The simulation for each model (i.e., stationary versus non-stationary) consists of three stages: stage 1: steady-state seepage using annual rain to generate initial conditions $(\mathrm{t}=0)$; stage 2: transient seepage using the corresponding 7-day precipitation extreme $(\mathrm{t}=1$ day to $\mathrm{t}=7$ days $)$; and stage 3: 8 days of transient seepage using annual rain to monitor the post-extreme rainfall behavior of the slope ( $t=8$ days to $t=15$ days). It is noted the stage 3 simulation was continued until $\mathrm{t}=40$ days, however no meaningful change was observed in pore-water pressures after $\mathrm{t}=$ 15 days. Initial conditions are achieved through a steady-state seepage analysis by imposing the infiltration boundary with baseline and projected rainfall intensities of 2.9 and $3.1 \mathrm{~mm} / \mathrm{d}$, separately. These rainfall intensities used to generate the initial conditions represent annual precipitation amounts for the study area. After the initial conditions are achieved in each model, 
a transient seepage analysis is conducted by imposing 7-day baseline and projected rainfall intensities of 45.4 and $69.5 \mathrm{~mm} / \mathrm{d}$, respectively, along the slope boundary. A seepage face condition is employed for the simulated rainfall intensities. Such condition permits runoff when the rainfall intensity exceeds the infiltration capacity of the soil. The location of the water table is fixed horizontally at 2 meters below the toe of the slope while the left, right, and bottom segments of the domain are considered to be no-flow boundaries.

Slope stability FE models calculate FS as the ratio of the average shear strength of the soil and the average shear stress exhibited along some critical slip plane. Typically, a FS of approximately 1.5 is recommended in the analysis of natural and engineered earthen slopes. Based on the aforementioned definition for FS, the current study employs the shear strength reduction (SSR) method in $\mathrm{RS}^{2}$ to determine the local SRF that brings the model slope to its limit state (i.e., FS = 1). This is executed by gradually increasing the reduced effective shear strength parameters until the slope reaches the point of failure.

\section{RESULTS AND DISCUSSIONS}

The variances between the commonly used historical and $95^{\text {th }}$ percentile of the projected 7-day extreme precipitations are evaluated here by associating their effects on the hydromechanical response of a natural earthen slope. The impacts of the two precipitation extremes are compared in terms of the displacements, pore-water pressures, degrees of saturation, suction stresses, and local strength reduction factor.

The impact of the differences between the means of future and past IDF estimates on pore-water pressures, degrees of saturation, suction stresses, and local strength reduction factor were found to be insignificant (not shown here). However, the results showed substantial differences between the $95^{\text {th }}$ percentile of the future projections relative to the baseline. In the 
remaining sections of this paper, projections indicate the $95^{\text {th }}$ percentile of the 20 climate models used for estimating future extreme precipitation. Figure 4 displays the simulated baseline and projected relative displacements (Figures 4a-4c), degrees of saturation (Figures 4d-4f), and porewater pressures (Figures 4g-4i) under the steady-state and transient unsaturated seepage conditions. As demonstrated in Figure 2, the results are plotted along three cross sections of A-A (toe), B-B (middle), and C-C (crest). The displacements for each cross-section are plotted relative to that under the initial condition (i.e., $\mathrm{t}=0$ ). As can be seen in Figure 4, the imposed baseline rainfall intensity underestimates the displacement, saturation, and pore-water pressure in the model slope over the entire rain duration. Under the initial conditions in Figure 4, the small variations in slope behavior along the three cross-sections are attributable to the $7.3 \%$ difference between the imposed annual baseline and projected rainfall intensities. As shown in the crosssection A-A, the toe exhibits the smallest displacement. This behavior is due to the shear resistance offered at the toe of any slope. At the onset of the 7-day extreme rainfall event, the difference between the displacement, saturation, and pore-water pressure under the simulated baseline and projected rain intensities becomes more evident.

In Figure 4, the greatest change between the performance metrics under the baseline and projected precipitation extremes can be seen in the upper slope (i.e., cross-section C-C). The projected rainfall intensity in the upper slope prompts a sliding mechanism that is approximately $95 \%$ greater than that under the baseline conditions at $t=1$ day, for $z=0$. As shown, the projected rain degrades slope stability as much as 2 days faster than the baseline rain. For example, the displacements, saturations, and pore-water pressures along cross-sections B-B and $\mathrm{C}-\mathrm{C}$ are nearly identical under the baseline and projected rains, for $\mathrm{t}=5$ and 3 days, respectively. 
It is important to note that, these differences are attributed to the $53 \%$ increase in rain intensity from the stationary to the non-stationary condition considered herein.

As the 7-day rain persists in Figure 4, the stability of the slope under the projected rainfall at $\mathrm{t}=5$ days is less than that under the baseline rain at $\mathrm{t}=7$ days. Infiltration of water the into the slope under the projected rain intensity induces positive pore-water pressures at $\mathrm{t}=5$ days under an invariant total stress, which decreases the effective stress and, thereby reduces the soil shear strength, potentially leading to failure of the model slope. In contrast, while the amount of water infiltrating into the slope under the baseline rain shows to decrease the effective stress, negative pore-water pressures still remain at $\mathrm{t}=7$ days.

Figure 5 compares the impacts of the baseline and projected precipitation extremes on the simulated $S_{e}$ with time, for three different depths along each cross-section. Figures 5a through 5c show the simulated $S_{e}$ over the entire rainfall duration, whereas Figure $5 \mathrm{~d}$ through $5 \mathrm{f}$ demonstrate the relative percent change in $S_{e}$ between the stationary and the non-stationary condition. A positive change is symbolic of an increase in $S_{e}$ from the stationary to the non-stationary condition, whereas a negative change indicates a decrease in $S_{e}$. Figure 5a shows that the wetting front progresses beyond the toe of the slope at just 3 days after the heavy rain commences (i.e., $S_{e}=100 \%$ ). As can be seen, the upper slope (i.e., cross-section C-C) exhibits the greatest change in $S_{e}$ under the stationary and the non-stationary condition between $\mathrm{t}=1$ day and 3 days. This sudden change is a result of the difference in the pore-water pressure increase between the stationary and the non-stationary conditions. For example, a $40 \mathrm{kPa}$ increase in the pore pressure from $\mathrm{t}=1$ day to 3 days, at $\mathrm{z}=5 \mathrm{~m}$, under the projected rain prompts a $20 \%$ increase in $S_{e}$. In contrast, the baseline rain intensity only increases the pore-water pressure, for the same depth 
and time interval, approximately $20 \mathrm{kPa}$. The corresponding $S_{e}$ only increases by approximately $5 \%$.

Figure 6 shows the difference in the simulated suction stress over time between the baseline and projected precipitation extremes. The results are presented for three depths along each cross-section. The figure shows that $\sigma^{\mathrm{s}}$ in each cross-section, for $\mathrm{t}=0$, does not vary meaningfully between each of the imposed rainfall intensities. The minute difference is attributable to the insignificant change between the baseline and projected annual precipitation extremes. As shown, the difference in $\sigma^{\mathrm{s}}$ between the baseline and projected rain intensities is more evident at the onset of the 7-day heavy rain (see Figures $6 \mathrm{~d}-6 \mathrm{f}$ ). The upper slope at $\mathrm{t}=1$ day displays a $\sigma^{\mathrm{s}}$ under the non-stationary condition that is approximately 20,10 , and $5 \%$ greater than that under the stationary condition, for $\mathrm{z}=1,3$, and $5 \mathrm{~m}$, respectively. For the same section, the relative percent change in $\sigma^{\mathrm{s}}$ at $\mathrm{z}=1 \mathrm{~m}$ increases to a maximum of about $85 \%$ up to $\mathrm{t}=5$ days, while the relative percent change in $\sigma^{\mathrm{s}}$ is greatest at $\mathrm{t}=7$ days, for $\mathrm{z}=3$ and $5 \mathrm{~m}$.

The change in the simulated local values of the SRF with time, as predicted per the SSR method, is illustrated in Figures $7 \mathrm{a}$ through $7 \mathrm{c}$ for the three cross sections. Figures $7 \mathrm{~d}$ through $7 \mathrm{f}$ show the relative percent changes in the local SRF between the baseline and projected rain intensities. A positive change represents an increase in the local SRF from the stationary to the non-stationary condition, whereas a negative change indicates merely the opposite. As can be seen, the local SRF in cross-sections A-A and B-B never approaches the limit state (i.e., SRF = FS = 1), indicating that these sections within the slope remain rather stable. The magnitude of the local SRF exhibited at the toe can possibly mean that the slope is near the brink of failure. The upper slope (i.e., cross-section C-C) appears to be unstable (i.e., SRF $<1$ ) under the nonstationary condition at just $\mathrm{t}=3.5$-days, for $\mathrm{z}=1 \mathrm{~m}$ below the infiltration boundary. Such 
behavior can be accredited to the rapid decrease in the shear resistance along the slip surface resulting from the large increase in the pore-water pressure under the non-stationary condition.

Figure 8 depicts the pore-water pressure field in the slope at different times under the stationary condition. Before the onset of the 7-day rainfall, the pore-water pressures vary almost linearly behind the infiltration boundary up to the depth of the water table and are more or less perpendicular to the slope surface. At the onset of the 7-day heavy rain, the pore-water pressure contours exhibit a lens shape, indicating that pore pressures are closer to zero at $\mathrm{z}=0 \mathrm{~m}$. At the end of the 7-day rainfall, the rain intensity is equal to the initial conditions (i.e., annual rain) to bring the slope to a steady-state. As a result, it can be seen that the negative pore-water pressures still contribute to the stability of the slope at $\mathrm{t}=15$ days.

Figure 9 displays the pore-water pressure field in the slope at different times under the non-stationary condition. The shape of the wetting front in the first few meters below the upper slope boundary is most likely a manifestation of the projected rainfall intensity superseding the moisture holding capacity of the soil; similar behavior was seen under the baseline rainfall (Figure 8). As illustrated, the projected precipitation extreme, in comparison to the baseline extreme, has a more profound impact on the magnitude of the pore-water pressure and shape of the wetting front. For instance, the pore pressure contours under the non-stationary condition at $t$ $=7$ days are identical to those at $\mathrm{t}=15$ days under the stationary condition. Figure 9 also shows that suction is no longer contributing to the stability of the slope at $t=15$ days under the nonstationary condition. In fact, the pore-water pressure is approximately $5 \mathrm{kPa}$ at $\mathrm{t}=15$ days under the projected rainfall. Such a significant increase in the pore-water pressure (i.e., more than a $100 \%$ increase from $t=0$ to $t=15$ days) can lead to a substantial reduction in the soil shear strength. Retrospectively, the pore pressure contours in Figure 9 show that the projected rain 
intensity increases the rate at which the wetting front progresses with depth, which in turn increases the failure probability of the slope.

Figure 10 demonstrates the impact of the imposed baseline rain intensity on the SRF. As can be seen, the SRFs are highest locally just above the toe of the slope for all of $t$, whereas the crest appears to become unstable at just $t=3$ days. Beyond $t=3$ days, the impacts of the imposed rain intensity become more apparent around the upper, middle, and lower slope boundaries. The contours near the infiltration boundary of the middle slope follow a similar localized failure mechanism that is consistent with field observations of shallow landslides (e.g., Cruden and Varnes 1996).

Figure 11 demonstrates the change in the local SRF under the projected precipitation extremes. As can be seen, the slope appears to be stable under the initial conditions. Once the heavy rainfall commences at $\mathrm{t}=1$ day, however, localized tension (represented by the red zones in Figure 11) can be seen in the middle and upper slope boundaries. As the projected rain persists up to $t=3$ days, the slope boundary approaches the limit state. Beyond $t=3$ days, the amount of tension in the slope increases, which is indicative of active landsliding. In fact, the behavior of the contours around the middle slope boundary also follows a similar localized failure mechanism consistent with that observed from studies of shallow landslides. In Figure 11, the increase in the thickness of tension zone with depth is a result of the quick advancement of the wetting front with time, which is in part due to the magnitude of the projected rainfall intensity and permeability and porosity of the soil. Additionally, the behavior of the middle slope under the non-stationary condition shows a tension zone at $\mathrm{t}=1$ day, whereas the stationary model exhibits a similar tension zone as much as 14 days later. 


\section{CONCLUSIONS}

An increase in the statistics of extremes (e.g., increased rainfall intensity) due to a changing climate highlights the need to quantify the effects of these extremes on the resilience of natural and engineered earthen structures. Increased rainfall intensity can escalate the pore-water saturation in unsaturated soils leading to significant reductions in the soil suction and soil strength. The aim of this study was to quantitatively compare the influence of stationary (baseline) and non-stationary (projected) Intensity-Duration-Frequency (IDF) curves obtained for the Seattle area on the stability of a natural earthen slope. The stationary and non-stationary IDF curves were implemented into a series of fully coupled 2D steady-state and transient unsaturated seepage finite element (FE) simulations. The comparisons between the baseline and projected precipitation extremes were presented here for a homogeneous silty soil slope located in the Seattle region. The stationary and non-stationary FE models were compared in terms of displacements, degrees of saturation, matric suctions, suction stresses, and local strength reduction factors.

Generally, a higher rain intensity can expose an engineered slope or earth retaining structure to significant increases in pore pressures. This increase can lead to destabilization in a slope or increases in active earth pressures behind the wall of a retaining structure. The goal of this study was to raise awareness regarding impacts that increased rain intensity in the future climate can have on not only natural slopes, but also engineered slopes and earth retaining structures. The presented model did not show substantial impacts on the slope stability when considering the mean of the future precipitation extremes. The presented model did, however, indicate that there is a need to reevaluate existing infrastructure design and maintenance guidelines when considering the $95^{\text {th }}$ percentile of the projected precipitation extremes from 
climate models. It is imperative to consider the aforesaid precipitation extremes to ensure that our geotechnical structures can safely handle the extra load of water resulting from an increase in future rain intensity. Furthermore, we note that similar scenarios should also be considered for engineered slopes and earthen structures to assess their resilience under a changing climate.

This study integrated geotechnical engineering with hydrology and climate science, to quantify how climate change-induced changes in extreme precipitations may affect the performance of a slope. The modeling approach introduced in this paper can be applied to other geotechnical engineering structures, other regions and climate extremes as well, to address the direct impact of climate change on geotechnical infrastructure. Adopting the proposed approach can provide an excellent opportunity for the broader geotechnical engineering community to investigate whether climate change matters to geotechnical engineering and to what degree.

\section{ACKNOWLEDGEMENT}

The authors would like to thank Elisa Ragno for her assistance in obtaining the IDF curves used in this study.

\section{REFERENCES}

ASCE. 2015. Adapting infrastructure and civil engineering practice to a changing climate, American Society of Civil Engineers, http://ascelibrary.org/doi/pdf/10.1061/ 9780784479193.

Bishop, A. W. 1959. “The principle of effective stress.” Tek. Ukeblad, 106(39), 859-863.

Bonnin, G.M., Martin, D., Lin, B., Parzybok, T., Yekta, M., and Riley, D. 2006. "Precipitationfrequency atlas of the United States." NOAA Atlas 14, 1 - 64. 
Cascini, L., Cuomo, S., Pastor, M., and Sorbino, G. 2010. "Modeling of Rainfall-Induced Shallow Landslides of the Flow-Type." J. Geotech. Geoenviron. Eng., 136(1), 85-98.

Cascini, L., Cuomo, S., Pastor, M., and Sacco, C. 2013. "Modelling the post-failure stage of rainfall-induced landslides of the flow type." Canadian Geotech. J., 50(9): 924-934.

Casini, F., Serri, V., and Springman, S.M. 2013. "Hydromechanical behaviour of a silty sand from a steep slope triggered by artificial rainfall: from unsaturated to saturated conditions." Canadian Geotech. J., 50(1): 28-40.

Cheng, L., and AghaKouchak, A. 2014. "Non-stationary precipitation Intensity-DurationFrequency curves for infrastructure design in a changing climate." Scientific Reports, 10.1038/srep07093, 7093.

Cheng, L., AghaKouchak, A., Gilleland, E., and Katz, R.W. 2014. "Non-stationary Extreme Value Analysis in a Changing Climate”, Climatic Change, 127(2), 353-369.

Coe, J.A. and Godt, J.W. 2012. Review of approaches for assessing the impact of climate change on landslide hazards, In: Landslides and Engineered Slopes, Protecting Society Through Improved Understanding, Proceedings of the 11th International and 2nd North American Symposium on Landslides and Engineered Slopes, E. Eberhardt, C. Froese, A.K. Turner, and S. Leroueil, eds. Banff, Canada, 3-8 June 2012, Taylor \& Francis Group, London, v. 1, 371377.

Coles, S., Bawa, J., Trenner, L. and Dorazio, P. 2001. An introduction to statistical modeling of extreme values, Springer, London.

Crozier, M. J. 2010. "Deciphering the effect of climate change on landslide activity: a review." Geomorphology, 124, 260-267. 
Cruden, D. M., and Varnes, D. J. 1996. "Landslide types and processes, in Landslides: Investigation and Mitigation, Transportation Research Board Special Report”, 247, 36-75, edited by A. K. Turner and R. L. Schuster, Natl. Acad. Press, Washington, D.C.

Farahmand, A., and AghaKouchak, A. 2013. "A Satellite-Based Global Landslide Model”, Natural Hazards and Earth System Sciences, 13, 1259-1267, doi:10.5194/nhess-13-12592013.

Fredlund, D. G., and Rahardjo, H. 1993. Soil Mechanics for Unsaturated Soils, John Wiley \& Sons, Inc., New York, 517 pp.

Gregersen, I. B., Madsen, H., Rosbjerg, D., and Arnbjerg-Nielsen, K. 2013. “A spatial and nonstationary model for the frequency of extreme rainfall events." Water Resour Res, 49(1), $127-136$.

Griffiths, D.V., and Lu, N. 2005. "Unsaturated slope stability analysis with steady infiltration or evaporation using elasto-plastic finite elements." Int. J. Numer. Analyt. Meth. Geomech., $29(3), 249-267$.

Iverson, R.M., George, D.L., Allstadt, K., Reid, M.E., Collins, B.D., Vallance, J.W., Schilling, S.P., Godt, J.W., Cannon, C.M., Magirl, C.S., Baum, R.L., Coe, J.A., Schulz, W.H., and Bower, J.B. 2015. "Landslide mobility and hazards: implications of the 2014 Oso disaster." Earth and Planetary Sci Letters, 412, 197 - 208.

Keaton, J.R., Anderson, S., Benoit, J., deLaChapelle, J., Gilbert, R., and Montgomery, D.R. 2014. “The 22 March 2014 Oso Landslide, Snohomish Country, Washington.” GEER Association Report No. GEER-036.

KMA. 2008. Report on climate change and mitigation, Korean meteorological administration, dept. of climate change response: climate change information center, (in Korean). 
Leshchinsky, B., Vahedifard, F., Koo, H.B., and Kim, S.H. 2015. "Yumokjeong Landslide: an investigation of progressive failure of a hillslope using the finite element method." Landslides, 12(5), 997-1005.

Lu, N., and Godt, J.W. 2008. Infinite slope stability under unsaturated seepage conditions, Water Resour. Res., 44, W11404, doi:10.1029/2008WR006976.

Lu, N., Godt, J.W., and Wu, D. T. 2010. "A closed-form equation for effective stress in unsaturated soil." Water Resour. Res., 46(5), W05515.

Lu, N., Şener-Kaya, B., Wayllace, A., and Godt, J.W. 2012. "Analysis of rainfall-induced slope instability using a field of local factor of safety." Water Resour Res, 48(9), W09524. doi:10.1029/ 2012WR01 1830.

Melchiorre, C. and Frattini, P. 2012. "Modelling probability of rainfall-induced shallow landslides in a changing climate", Otta, Central Norway. Climatic change, 113(2), 413-436.

Mualem, Y. 1976. "A new model for predicting hydraulic conductivity of unsaturated porous media." Water Resources Research, 12(3): 513-522.

NRC. 2008. Potential Impacts of Climate Change on US Transport. Committee on Climate Change and US Transportation, Transportation Research Board, Division on Earth and Life Studies, National Research Council of the National Academies Washington, DC, ISBN: 9780-309-11306-9, 296 pages.

NRC. 2013. Abrupt Impacts of Climate Change: Anticipating Surprises. Committee on Understanding and Monitoring Abrupt Climate Change and Its Impacts; Board on Atmospheric Sciences and Climate; Division on Earth and Life Studies; National Research Council of the National Academies, Washington, DC, ISBN: 978-0-309-28773-9, 250 pages. 
Robinson, J. D., and Vahedifard, F. 2016. "Weakening mechanisms imposed on California's levees under multiyear extreme drought." Climatic Change, 137(1), 1-14.

Schuster, R. L., and Highland, L. 2001. Socioeconomic and environmental impacts of landslides in the western hemisphere. US Department of the Interior, US Geological Survey.

Sidle, R.C. 2007. "Using weather and climate information for landslide prevention and mitigation.” In M.Y.K. Sivakumar \& N. Ndiang'ui (eds.), Climate and Land Degradation, 285- 307. Berlin: Springer.

Smith, I.M., and Griffiths, D.V. 1997. Programming the Finite Element Method, Third Edition, West Sussex, England: John Wiley and Sons Ltd.

Sorooshian, S., AghaKouchak, A., Arkin, P., Eylander, J., Foufoula-Georgiou, E., Harmon, R., and Skofronick-Jackson, G. 2011. "Advanced concepts on remote sensing of precipitation at multiple scales.” Bulletin of the American Meteorological Society, 92(10).

Ter Braak, C. J. 2006. "A Markov Chain Monte Carlo version of the genetic algorithm Differential Evolution: easy Bayesian computing for real parameter spaces.” Stat. Comput., $16,239-249$.

USGCRP. 2009. Global Climate Change Impacts in the United States, U.S. Global Change Research Program, Cambridge University Press, ISBN 978-0-521-14407-0.

Vahedifard, F., AghaKouchak, A., and Robinson. J. D. 2015a. "Drought Threatens California's Levees.”Science, 349(6250), 799, DOI: 10.1126/science.349.6250.799-a.

Vahedifard, F., Leshchinsky, B., Mortezaei, K., and Lu, N. 2015b. "Active earth pressures for unsaturated retaining structures.” J. Geotech. Geoenviron. Eng., 141(11), 04015048.

Vahedifard, F. and Robinson, J. D. 2016. “A Unified Method for Estimating the Ultimate Bearing Capacity of Shallow Foundations in Variably Saturated Soils under Steady Flow.” J. 
of Geotech. and Geoenviron. Eng., ASCE, 142(4), 04015095. DOI:

10.1061/(ASCE)GT.1943-5606.0001445, 04015095.

Vahedifard, F., Leshchinsky, D., Mortezaei, K., and Lu, N. 2016a. "Effective stress-based limit equilibrium analysis for homogenous unsaturated slopes." Int. J. Geomech., 10.1061/(ASCE)GM.1943-5622.0000554.

Vahedifard F., Robinson J.D., and AghaKouchak A. 2016b. "Can Protracted Drought Undermine the Structural Integrity of California's Earthen Levees?” J. of Geotech. and Geoenviron. Eng., 142(6), 02516001.

Vahedifard, F., Mortezaei, K., Leshchinsky, B. A., Leshchinsky, D., and Lu, N. 2016c. "Role of Suction Stress on Service State Behavior of Geosynthetic-Reinforced Soil Structures.” Transportation Geotechnics, DOI: 10.1016/j.trgeo.2016.02.002.

Vanapalli, S. K., Fredlund, D. G., Pufahl, D. E., and Clifton, A. W. 1996. "Model for the prediction of shear strength with respect to soil suction." Can. Geotech. J., 33(3), 379-392.

van Genuchten, M. T. 1980. "A closed form equation predicting the hydraulic conductivity of unsaturated soils." Soil Sci. Soc. Am., 44, 892-898.

Vardon, P. J. 2015. "Climatic influence on geotechnical infrastructure: a review." Environmental Geotechnics, 2(3), 166-174.

Voight, B., Janda, R.J., Glicken, H., and Douglas, P.M. 1983. "Nature and mechanics of the Mount St. Helens rockslide-avalanche of 18 May 1980.” Geotechnique, 33, 243-273.

Vrugt, J. A., Braak, C.J.F., Diks, C.G.H., Robinson, B.A., Hyman, J.M., and Higdon, D. 2009. “Accelerating Markov chain Monte Carlo simulation by differential evolution with selfadaptive randomized subspace sampling. Int J Nonlin. Sci. Num., 10(3), 273-290. 


\section{List of Tables}

Table 1 Material and hydraulic properties of silty sand used in fully coupled FE analysis

\section{List of Figures}

Figure 1 a) Baseline and b) Projected intensity duration frequency estimates, and c) Relative percent change in rainfall intensity for Seattle, WA using GEV distribution.

Figure 2 Finite Element (FE) mesh used in coupled transient unsaturated seepage analysis.

Figure 3 Soil-water characteristic curve (SWCC) and Hydraulic Conductivity Function (HCF) for silty soil (after Lu et al. 2012).

Figure 4 Simulated relative displacement, degree of saturation, and pore-water pressure within time between baseline and projected precipitation extremes along three cross-sections of the model slope.

Figure 5 Simulated effective degree of saturation $\left(S_{e}\right)$, along with percent relative change in time, for baseline and projected precipitation extremes along three cross-sections of the model slope.

Figure 6 Simulated suction stress $\left(\sigma^{\mathrm{s}}\right)$, along with percent relative change in time, for baseline and projected precipitation extremes along three cross-sections of the model slope.

Figure 7 Simulated strength reduction factor (SRF), along with percent relative change in time, for baseline and projected precipitation extremes along three cross-sections of the model slope.

Figure 8 Contours of simulated pore-water pressure at different times for the model slope under baseline precipitation extremes.

Figure 9 Contours of simulated pore-water pressure at different times for the model slope under projected precipitation extremes.

Figure 10 Contours of simulated strength reduction factor (SRF) at different times for the model slope under baseline precipitation extremes.

Figure 11 Contours of simulated strength reduction factor (SRF) at different times for the model slope under projected precipitation extremes. 
Table 1 Material and hydraulic properties of silty sand used in fully coupled FE analysis

\begin{tabular}{lccc}
\hline \multicolumn{1}{c}{ Parameter } & Symbol & Unit & Value \\
\hline \hline Unit weight & $\gamma$ & $\mathrm{kN} / \mathrm{m}^{3}$ & 20 \\
\hline Young's Modulus & $\mathrm{E}$ & $\mathrm{kPa}$ & 10000 \\
\hline Poisson's Ratio & $v$ & - & 0.33 \\
\hline Cohesion & $\mathrm{c}^{\prime}$ & $\mathrm{kPa}$ & 10 \\
\hline Angle of friction & $\phi^{\prime}$ & $\mathrm{degrees}$ & 30 \\
\hline Saturated volumetric water content & $\theta_{\mathrm{s}}$ & - & 0.46 \\
\hline Residual volumetric water content & $\theta_{\mathrm{r}}$ & - & 0.034 \\
\hline Saturated hydraulic conductivity & $\mathrm{K}_{\mathrm{s}}$ & $\mathrm{m} / \mathrm{s}$ & $2.39 \mathrm{E}-06$ \\
\hline Fitting parameter related to pore-size distribution & $\mathrm{n}$ & - & 1.37 \\
\hline Fitting parameter related to air-entry pressure & $\alpha$ & $1 / \mathrm{m}$ & 1.6 \\
\hline
\end{tabular}



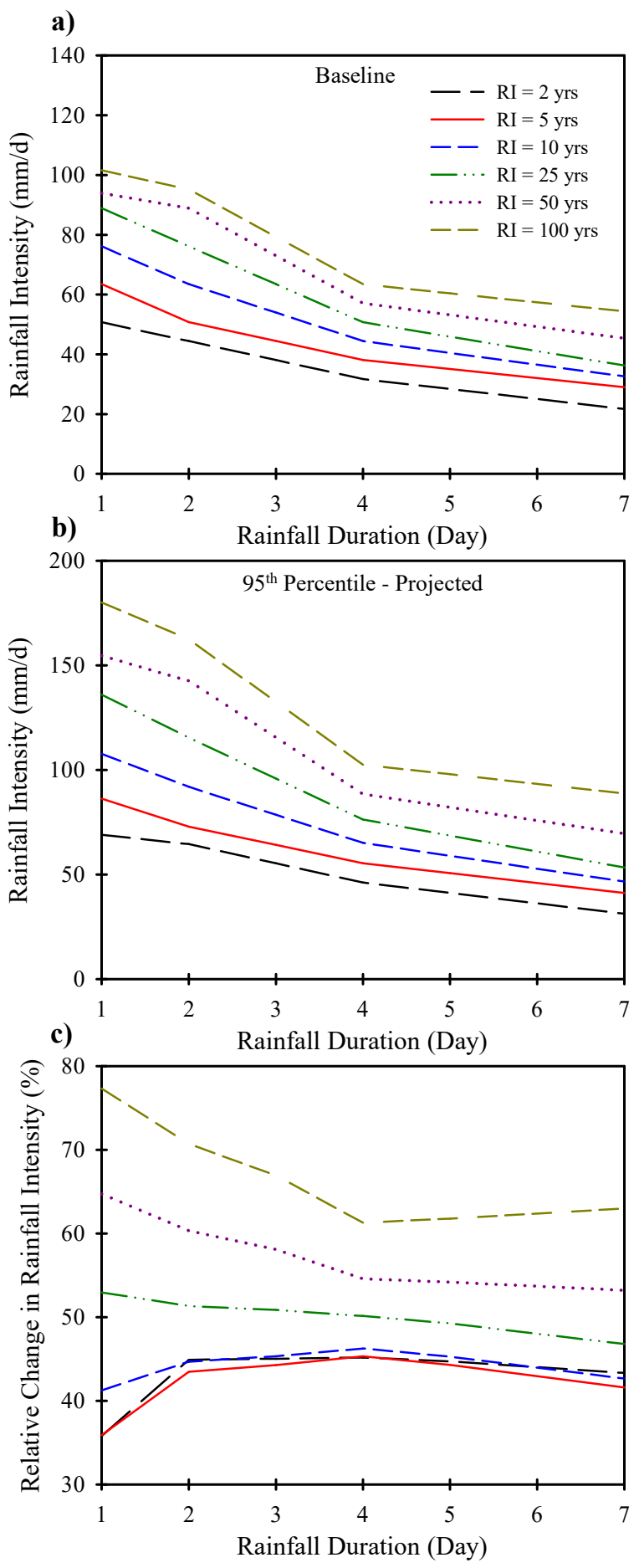

Figure 1 a) Baseline and b) Projected intensity duration frequency estimates, and c) Relative percent change in rainfall intensity for seattle, WA using GEV distribttps:ómc06.manuscriptcentral.com/cgj-pubs 


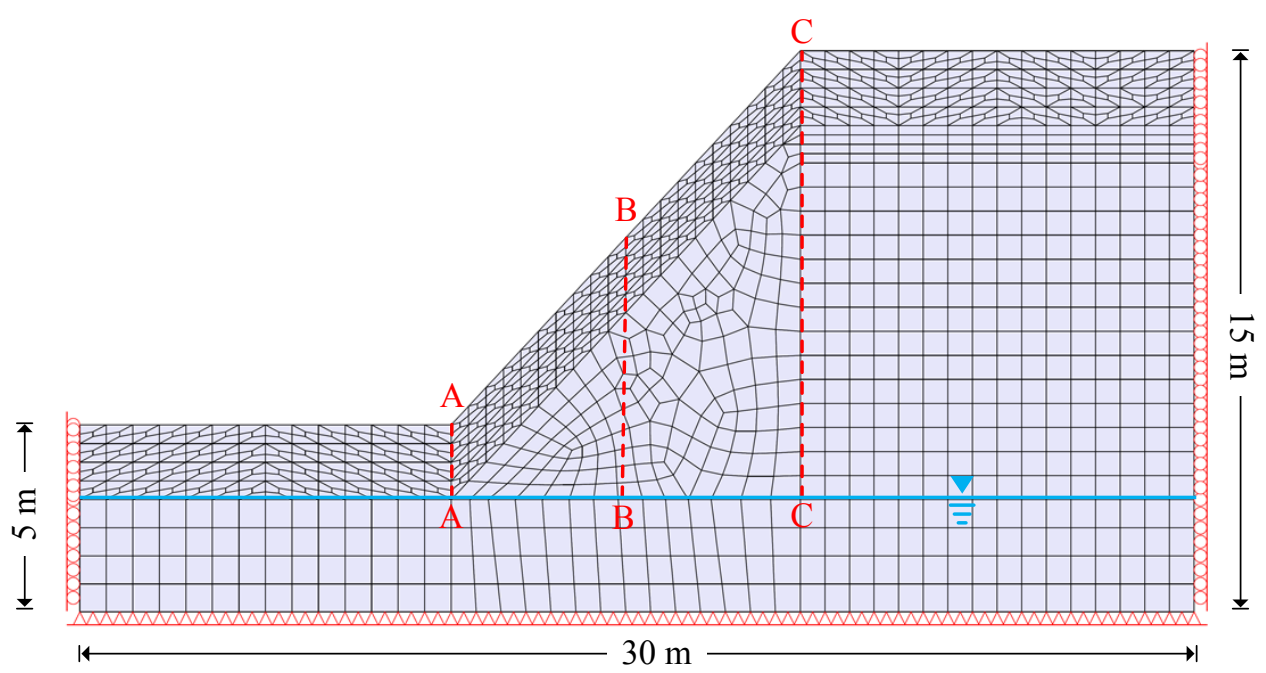

Figure 2 Finite Element (FE) mesh used in coupled transient unsaturated seepage analysis. 


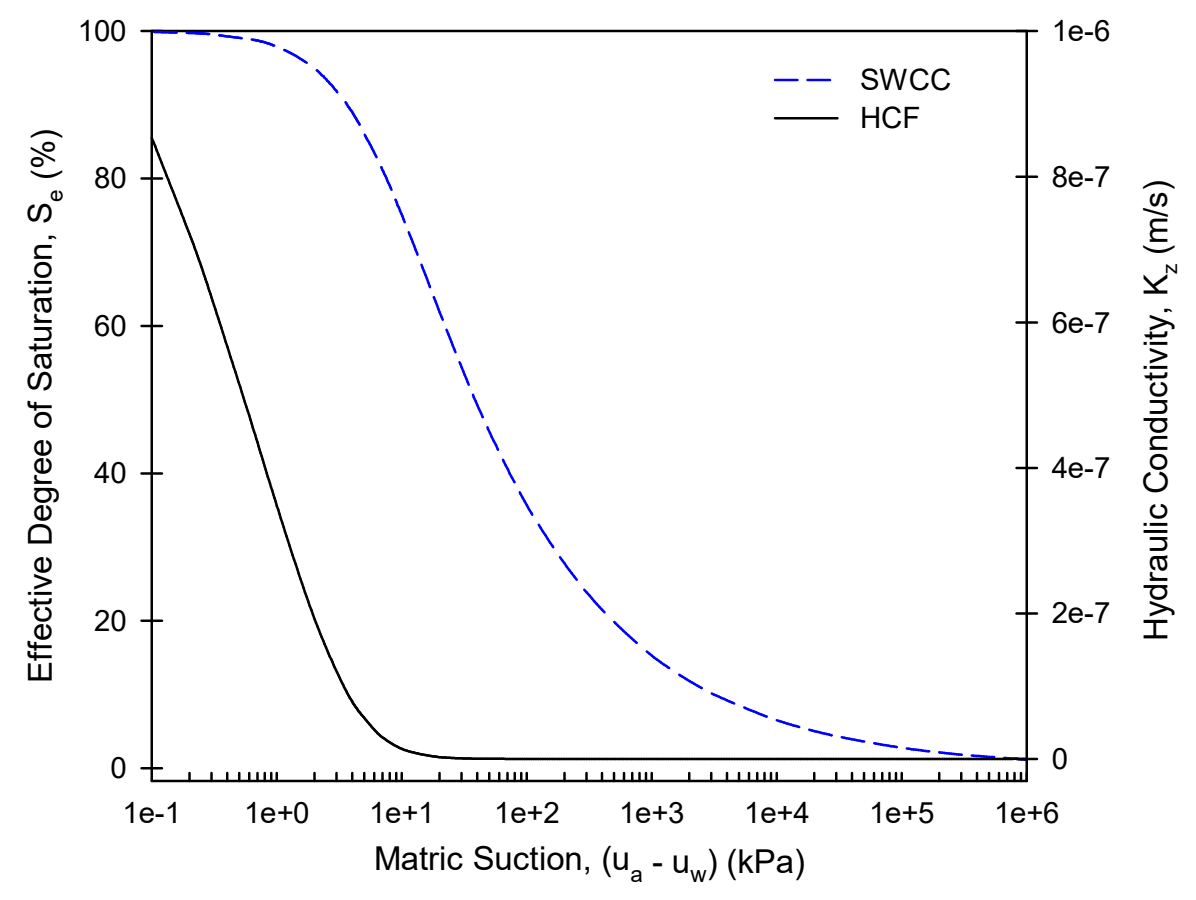

Figure 3 Soil-water characteristic curve (SWCC) and Hydraulic Conductivity Function (HCF) for silty soil (after Lu et al. 2012). 
a)

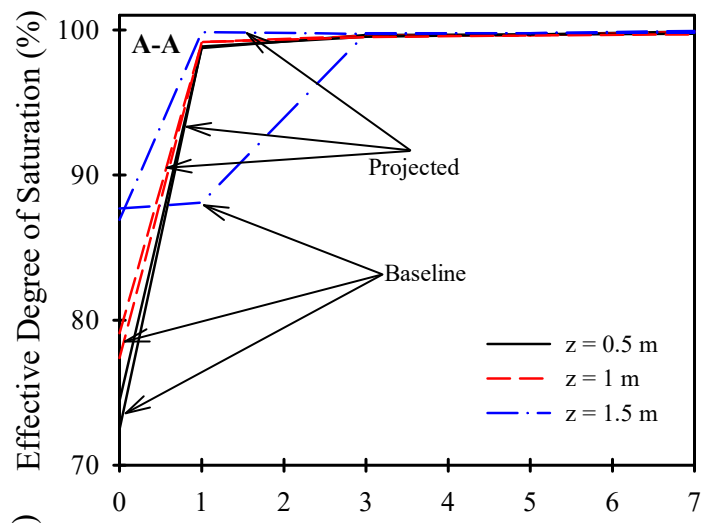

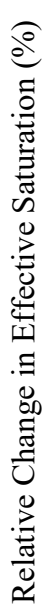

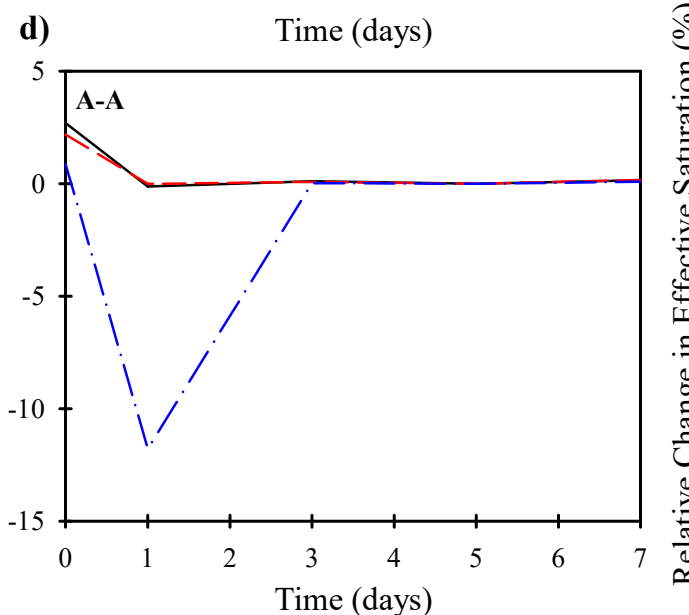

b)

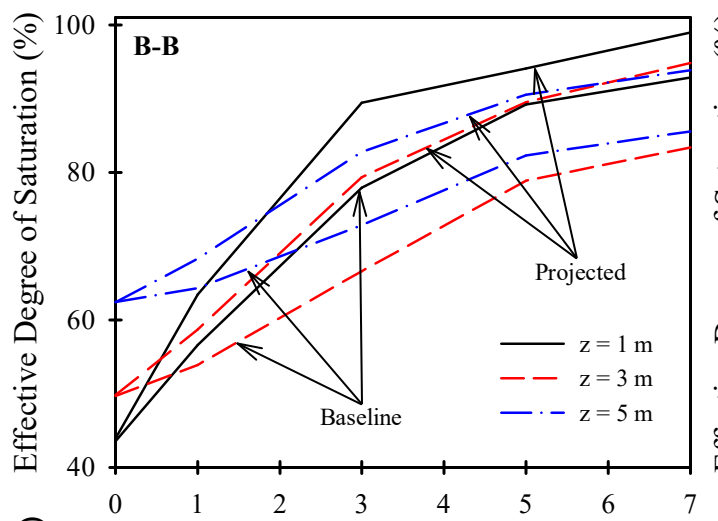

(อ)
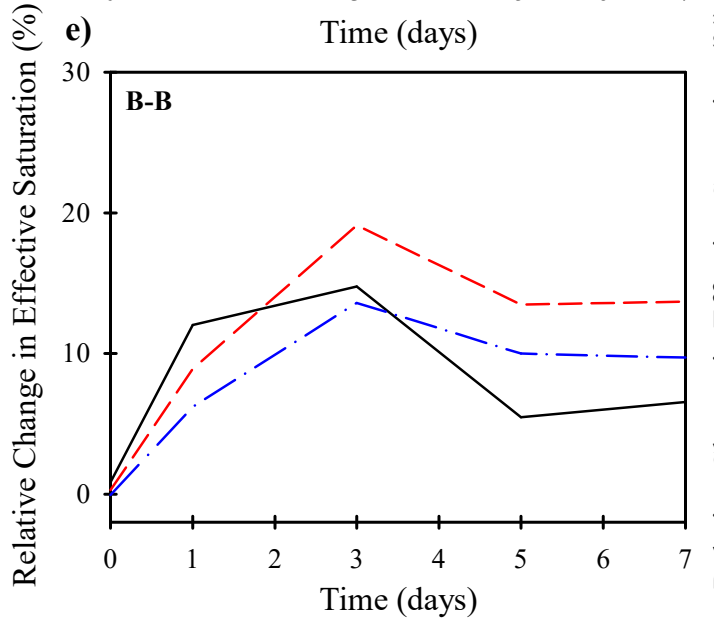

c)

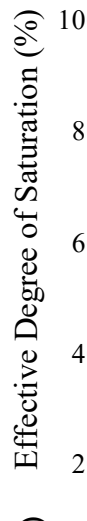

อ

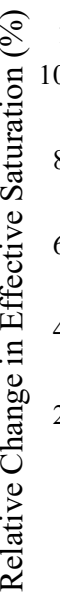

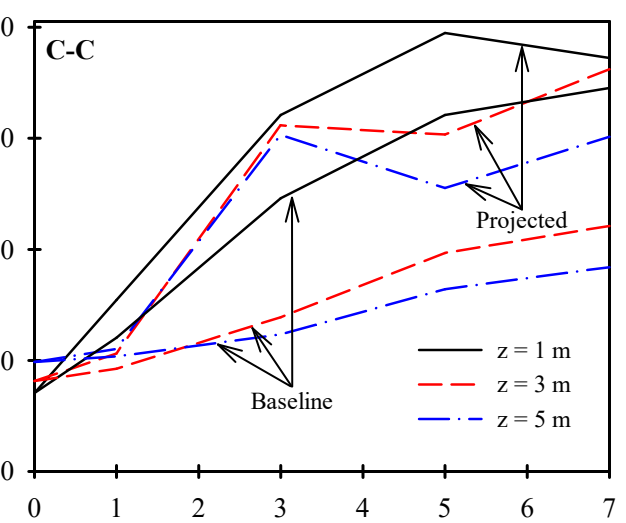

Time (days)

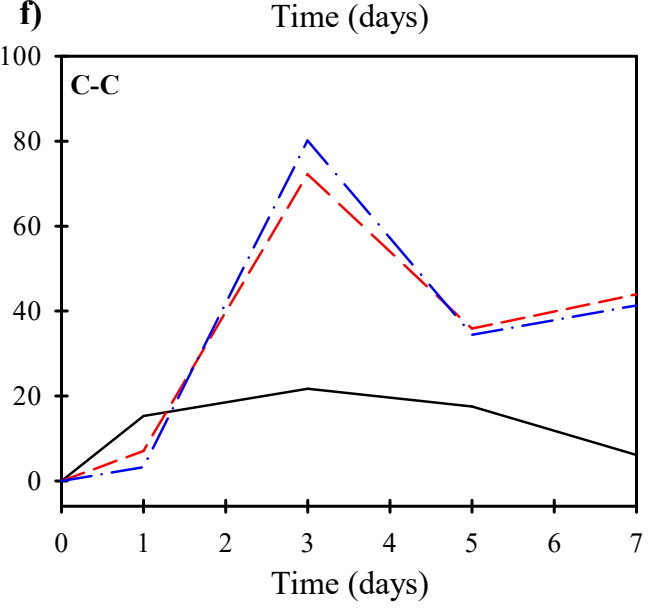

Figure 5 Simulated effective degree of saturation (Se), along with percent relative change in time, for baseline and projected precipitation extremes along three cross-sections of the model slope. 
a)

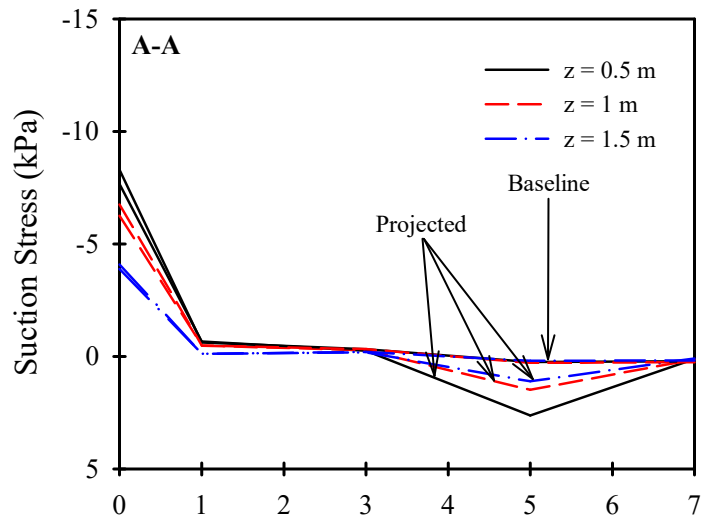

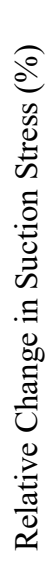

b)

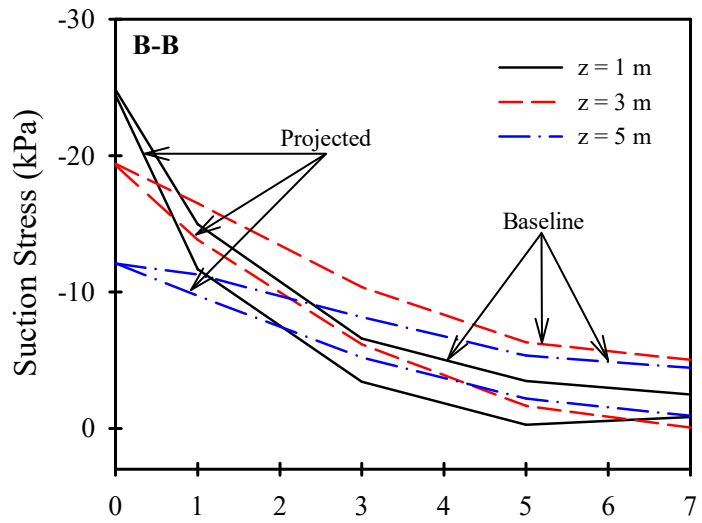

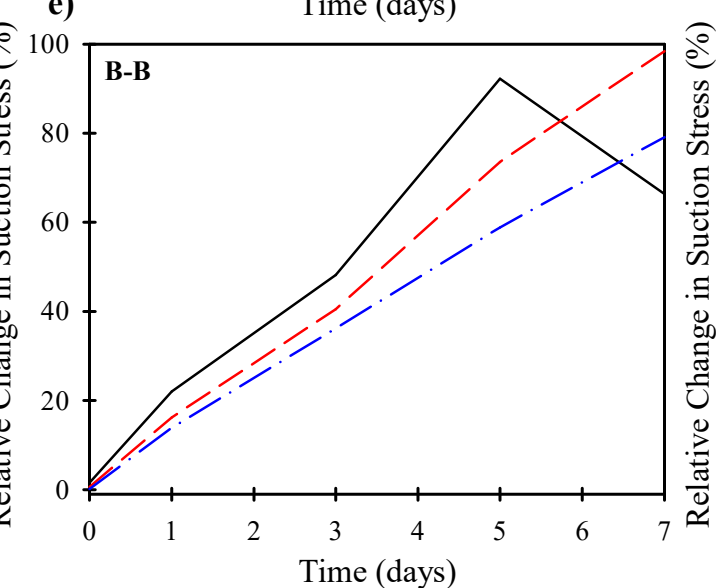

e)

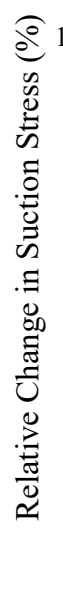

Time (days)

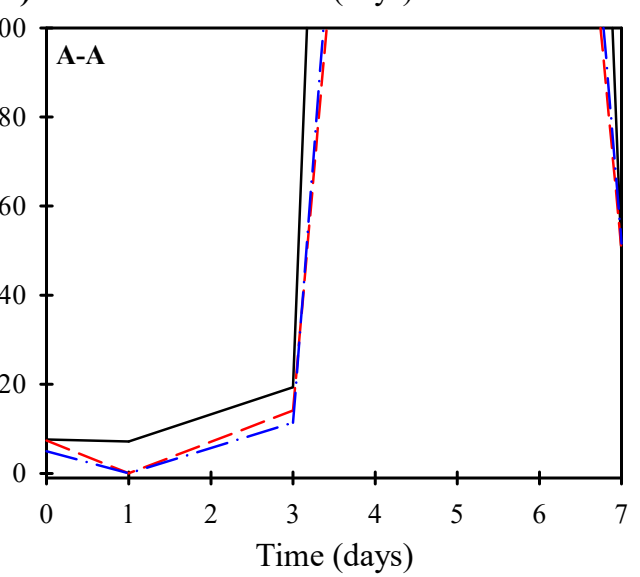

c)
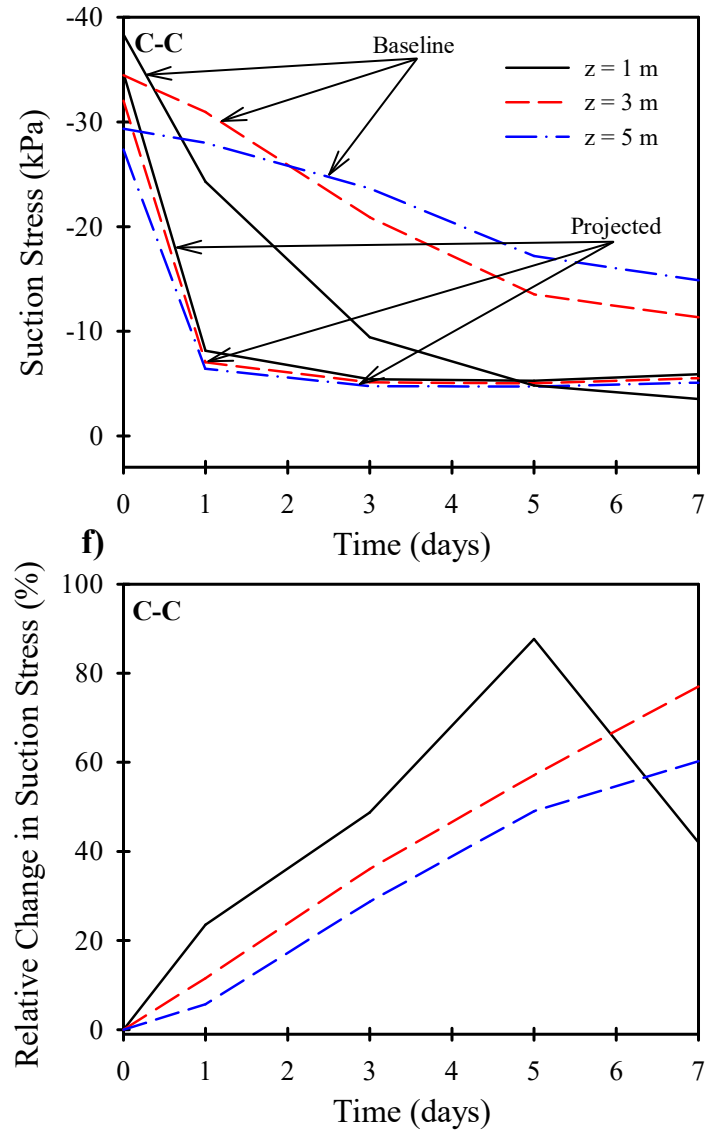

Figure 6 Simulated suction stress (os), along with percent relative change in time, for baseline and projected precipitation extremes along three cross-sections of the model slope. 
a)

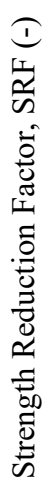

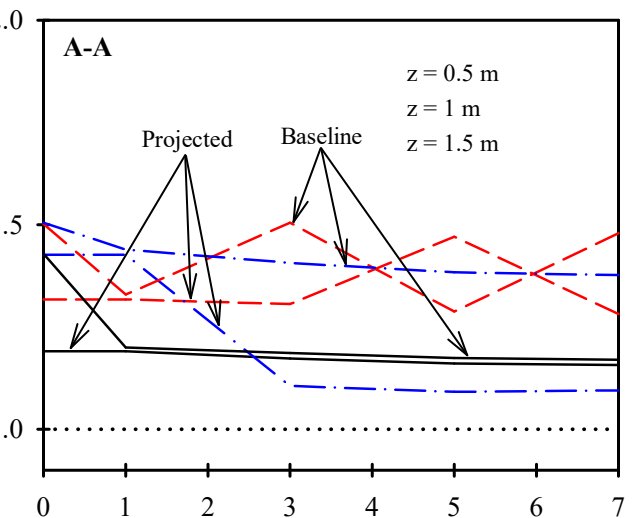

d)

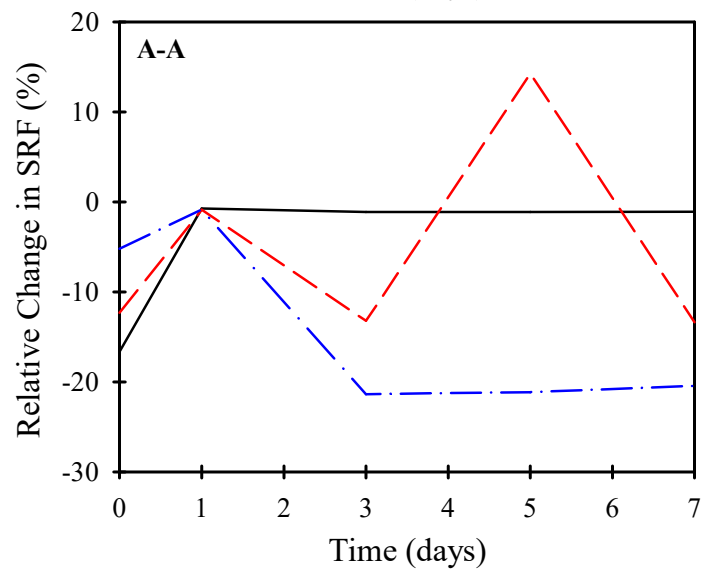

b)

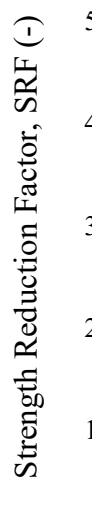

e)

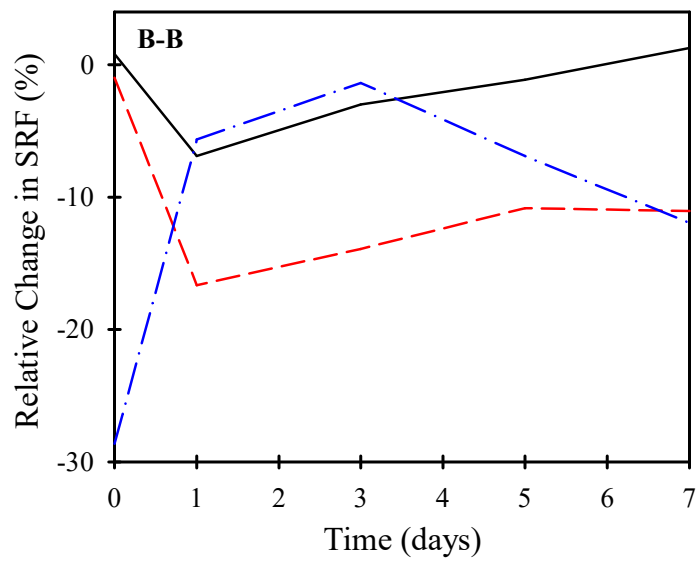

c)
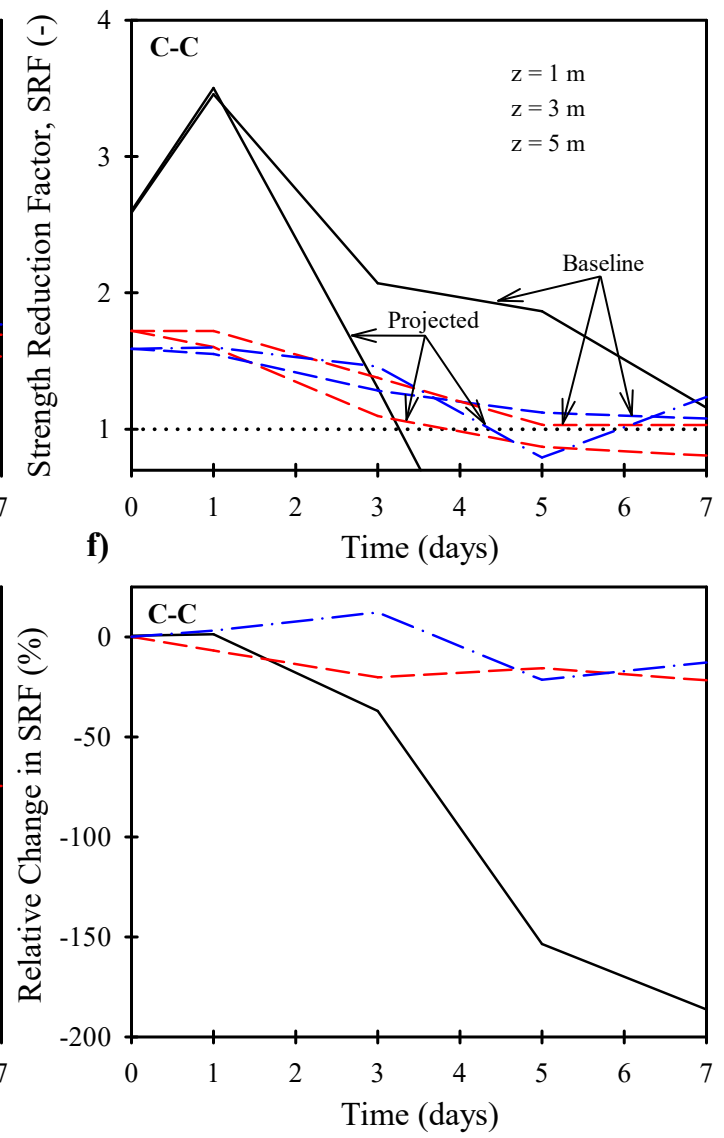

Figure 7 Simulated strength reduction factor (SRF), along with percent relative

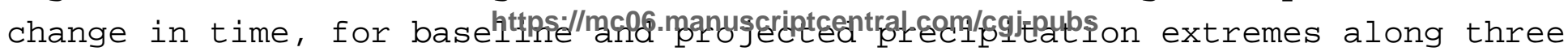
cross-sections of the model slope. 

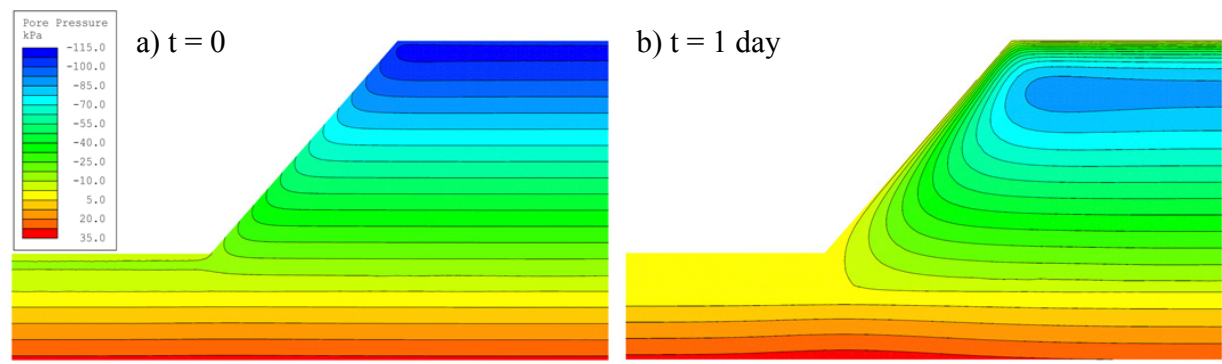

c) $t=3$ days

d) $\mathrm{t}=5$ days

e) $t=7$ days
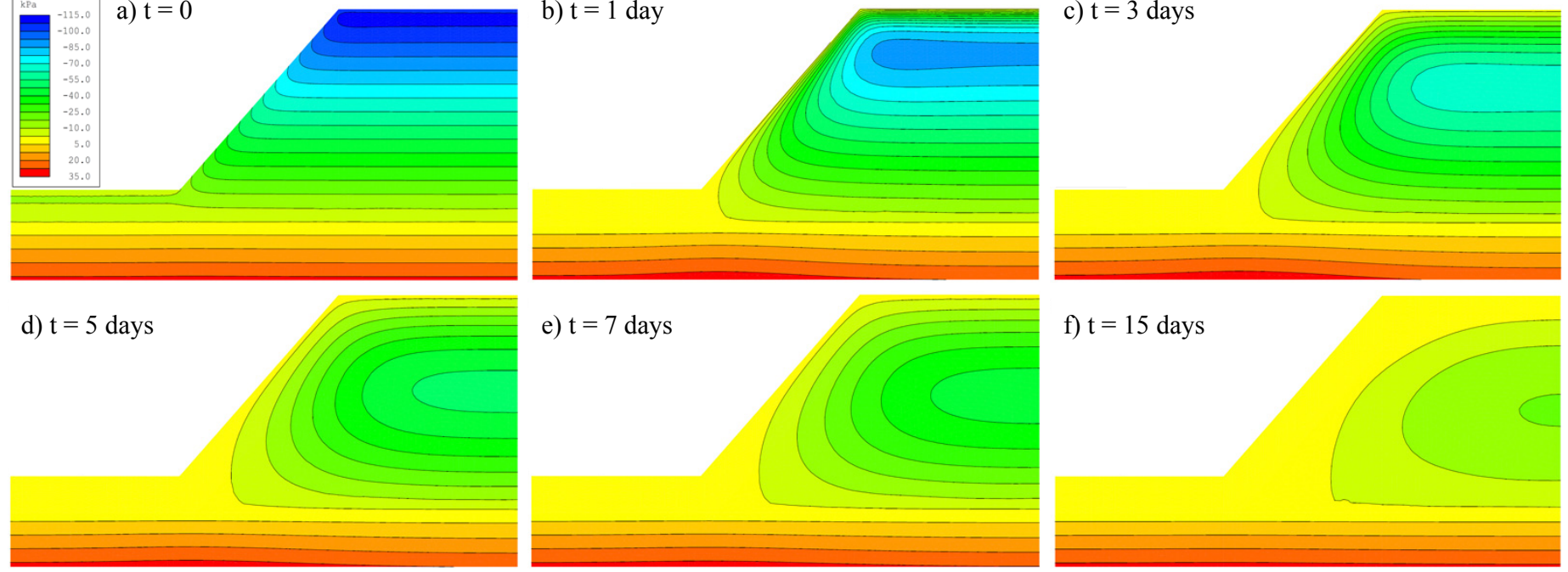

Figure 8 Contours of simulated pore-water pressure at different times for the model slope under baseline precipitation extremes. 


\section{Page 35 of 37}

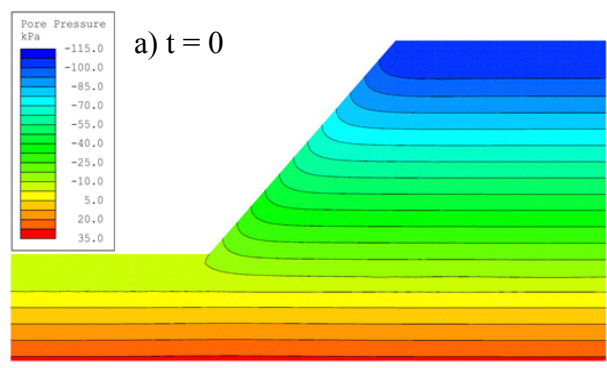

d) $t=5$ days

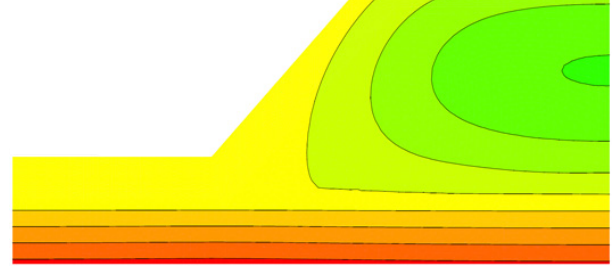

\section{Canadian Geotechnical Journal}

b) $t=1$ day

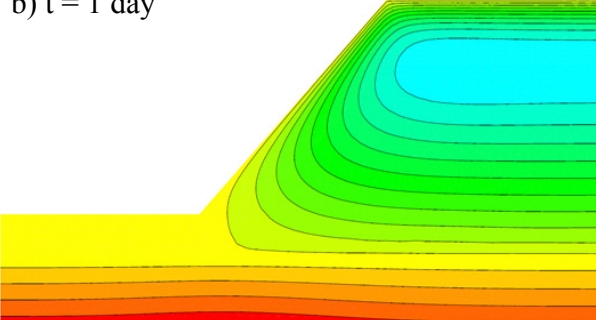

e) $t=7$ days

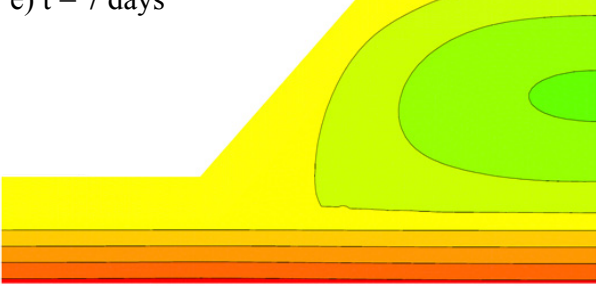

c) $t=3$ days

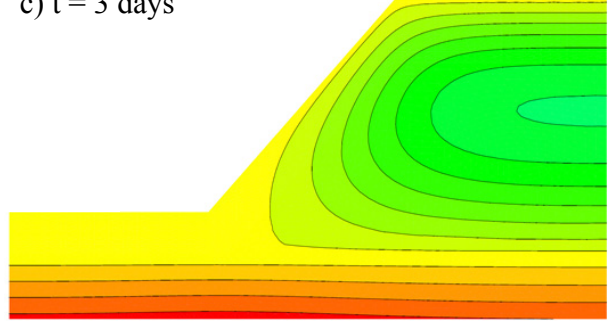

f) $t=15$ days

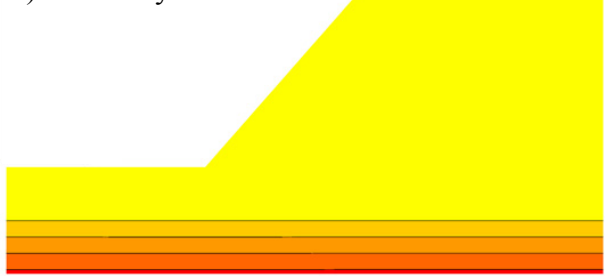

Figure 9 Contours of simulated pore-water pressure at different times for the model slope under projected precipitation extremes. 

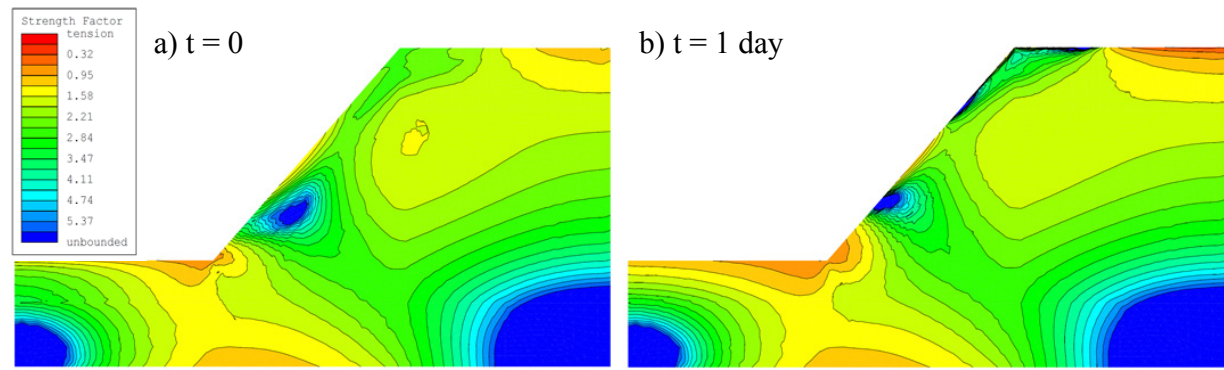

d) $t=5$ days

e) $t=7$ days

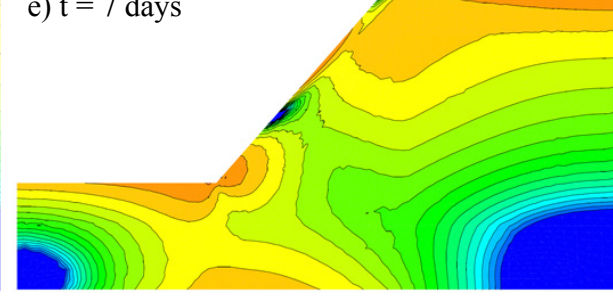

c) $t=3$ days

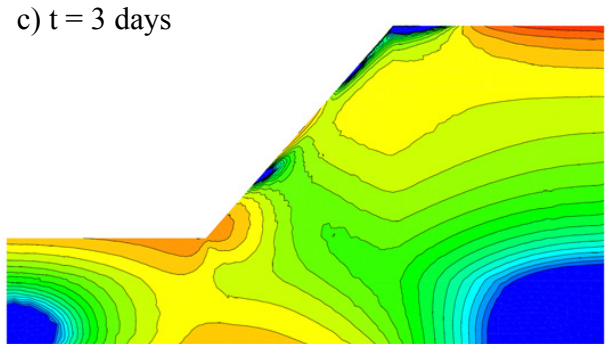

f) $\mathrm{t}=15$ days

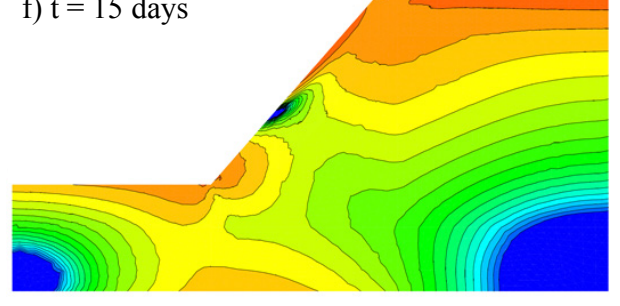

Figure 10 Contours of simulated strength reduction factor (SRF) at different times for the model slope under baseline precipitation extremes. 


\section{Page 37 of 37}

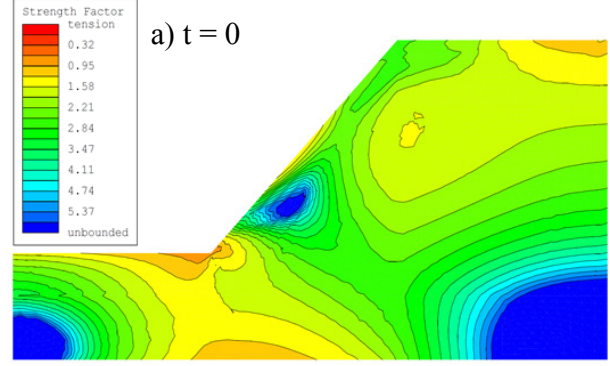

d) $t=5$ days

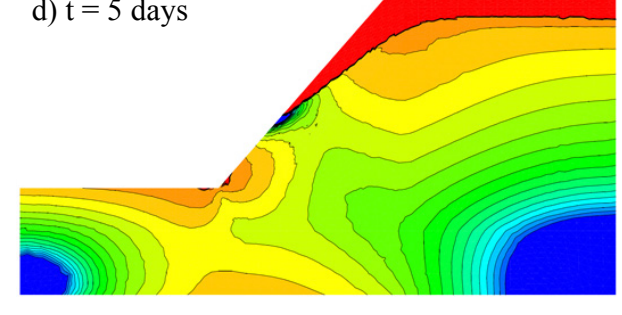

Canadian Geotechnical Journal

b) $t=1$ day

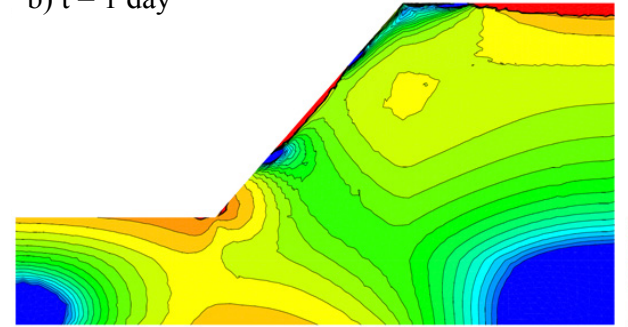

e) $t=7$ days

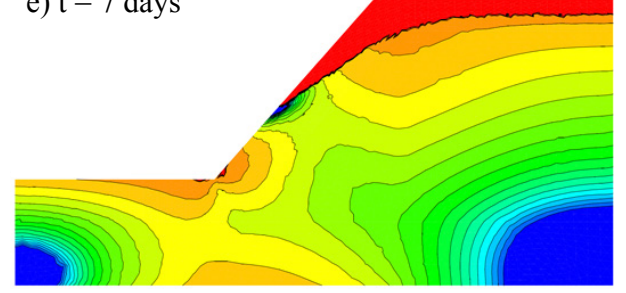

c) $t=3$ days

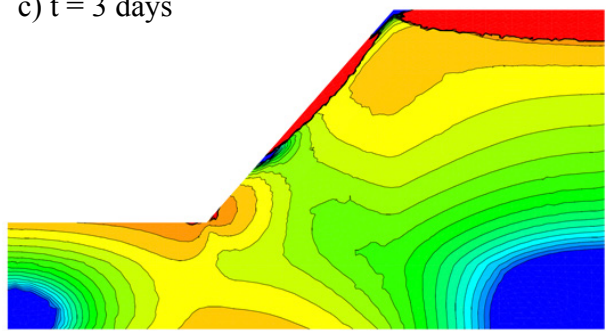

f) $\mathrm{t}=15$ days

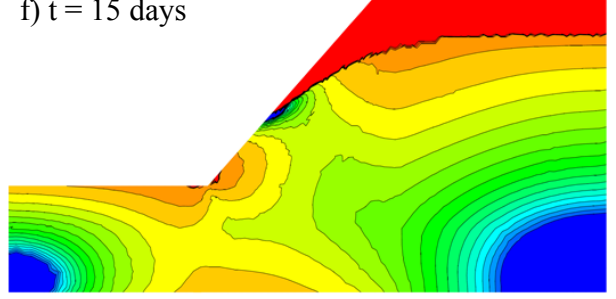

Figure 11 Contours of simulated strength reduction factor (SRF) at different times for the model slope under projected precipitation extremes. 